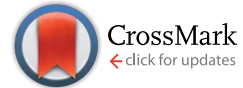

Cite this: J. Mater. Chem. A, 2015, 3 , 8171

Received 5th January 2015

Accepted 7th March 2015

DOI: $10.1039 / \mathrm{c} 5 \mathrm{ta} 00078 \mathrm{e}$

www.rsc.org/MaterialsA

\title{
Nickel nitride as an efficient electrocatalyst for water splitting $\dagger$
}

\author{
Menny Shalom, * Debora Ressnig, Xiaofei Yang, Guylhaine Clavel, Tim Patrick Fellinger \\ and Markus Antonietti
}

Efficient, robust and low cost materials as electrocatalysts for energy-related applications are highly desired for the future of renewable energy production. Here we show a simple method to fabricate nickel nitride $\left(\mathrm{Ni}_{3} \mathrm{~N}\right)$ on nickel $(\mathrm{Ni})$ foam for electrocatalytic applications. The $\mathrm{Ni}_{3} \mathrm{~N} / \mathrm{Ni}$-foam exhibits extremely low overpotential ( $\sim 50 \mathrm{mV}$ ), high current density and excellent stability for the hydrogen evolution reaction (HER) in alkaline solution. In addition, the modified foam demonstrates enhanced activity in the oxygen evolution (OER) and reduction (ORR) reaction compared to original Ni-foam. The activity enhancement can be attributed to the facile formation of a $\mathrm{Ni}(\mathrm{OH})_{2}$ layer on the nitride layer due to improved lattice matching. The formation of the $\mathrm{Ni}_{3} \mathrm{~N} / \mathrm{Ni}(\mathrm{OH})_{2}$ catalyst results in lower overpotentials due to easier water dissociation on the nickel hydroxide layer. In addition, the HER is further improved due to stronger adsorption of hydrogen to the metal nitride than to the pure metal. We believe that the utilization of nickel nitride as an electrocatalyst opens opportunities for energy-related devices such as batteries and fuel cells.

\section{Introduction}

The development of new electrocatalysts for water-splitting applications is a key challenge for the future of clean and renewable energy production. ${ }^{1,2}$ The two reactions that water splitting comprises are the hydrogen evolution reaction (HER) and the oxygen evolution reaction (OER). ${ }^{3}$ The HER is extremely important for the production of clean fuels and in electrolyzer cells, ${ }^{4}$ while the OER, along with the oxygen reduction reaction (ORR) is of great interest for many energy-related devices such as metal air batteries, electrolyzers, and fuel cells. ${ }^{5}$ In the last years, significant progress in the development of new HER, OER and ORR catalysts has been made, alongside fundamental studies regarding the nature of the corresponding reaction mechanisms. Nevertheless, there is still a real need for new materials to efficiently catalyze these reactions. The desired electrocatalysts should demonstrate low overpotential and high current densities for the given reaction in order to enhance the overall energy conversion efficiency. Up to now, and despite the development of new electrocatalysts that are based on nonnoble and earth-abundant metals (i.e. metal alloys, ${ }^{6,7}$ metal carbides and nitrides ${ }^{8}$ and molecular metal complexes ${ }^{9}$ ), the most efficient catalysts still consists of precious metals such as

Max Planck Institute of Colloids and Interfaces, Department of Colloid Chemistry, Research Campus Golm, 14424 Potsdam, Germany. E-mail: menny.shalom@mpikg. mpg.de

$\dagger$ Electronic supplementary information (ESI) available: Further chemical (XRD, SEM, FIB and XPS) and electrochemical characterizations. See DOI: 10.1039/c5ta00078e
Pt, Ir and Ru. ${ }^{10}$ One promising class of non-precious metal catalysts for energy-related devices are based on nickel, its alloys $\left(\mathrm{NiCo},{ }^{7} \mathrm{NiMo},{ }^{11} \mathrm{NiFe}^{12}\right.$ ) or the corresponding metal oxides. ${ }^{13}$ In particular, Ni-foams, which have originally been used as electrode-support in batteries, are interesting for electrocatalysis due to their high specific and electrochemically accessible surface area, which results in high current densities. ${ }^{14}$ In addition, Ni-foams are remarkably stable in alkaline solution and can be manufactured on a large scale with diverse surface and structure modifications.

As an alternative to metals and their oxides, metal nitrides attract a lot of attention thanks to their excellent catalytic activities in a variety of reactions for energy related applications. ${ }^{2,15,16}$ Metal nitrides (Ni-Mo-N or Co-Mo-N) show particularly high activity as electrocatalysts towards the HER. ${ }^{17}$ Moreover, theoretical calculations predict that metal nitride electrocatalysts possesses many advantages over the pure metals. $^{2}$ In the hydrogen evolution reaction, the superior activity of the metal nitride is explained on the one hand by the high binding energy for hydrogen, which results in higher hydrogen adsorption to the metal nitride surface. On the other hand, the presence of nitrogen strongly influences the electronic properties of the metal by increasing the density of electrons on the surface. Consequently, metal nitrides are found to have higher (electro)catalytic activities in reduction reactions, compared to the corresponding pure metals. ${ }^{2,16-18}$ Another strategy to enhance the performance of $\mathrm{Ni}$ in the HER through synergistic effects, was shown recently by the deposition of $\mathrm{Ni}(\mathrm{OH})_{2}$ onto Ni electrodes. ${ }^{19,20}$ The improvement of the 
catalytic performances was explained by better water dissociation by the $\mathrm{Ni}(\mathrm{OH})_{2}$ near the metal which leads to higher hydrogen adsorption on the $\mathrm{Ni}$.

Here, we show the facile, direct growth of nickel nitride $\left(\mathrm{Ni}_{3} \mathrm{~N}\right)$ on $\mathrm{Ni}$-foam by solid state synthesis for electrocatalytic applications. The growth of the material was achieved by using supramolecular complexes of cyanuric acid, melamine and small amounts of barbituric acid (referred here as CMB). The modification of the $\mathrm{Ni}$-foam results in the formation of a rough $\mathrm{Ni}_{3} \mathrm{~N}$ layer at the electrode surface, covered with carbon nitride, which can be removed with repeated cyclic voltammetry scans. The modified foam exhibits high electrocatalytic activity in the OER, ORR and especially in the HER.

\section{Results and discussion}

The direct growth of the $\mathrm{Ni}_{3} \mathrm{~N}$ layer was achieved by covering the Ni-foam with the supramolecular CMB complex. The complex was prepared simply by mixing $1: 1: 0.1$ cyanuric acid, melamine and barbituric acid in water ${ }^{21}$ (detailed information is given in the Experimental part). A thin layer of the solid complex was placed between and on top of two Ni-foams and heated to the desired temperature for 4 hours in a ceramic crucible under a nitrogen atmosphere with a heating ramp of $2.3 \mathrm{~K} \mathrm{~min}^{-1}$. After the reaction, the electrodes were cleaned with a strong air stream in order to remove loose excess material (characterizations of the removed powder are shown in Fig. S1†). The residual carbon-nitride-like powder could be subsequently removed by running up to 500 cyclic voltammetry cycles as discussed later in this manuscript.

In order to study the synthesis intermediates and products, we heated the mixture to different temperatures, from $475^{\circ} \mathrm{C}$ up to $600{ }^{\circ} \mathrm{C}$. Fig. S2 $\uparrow$ shows temperature-dependent X-ray diffraction (XRD) patterns of the modified Ni-foam. At the lowest temperature $\left(475{ }^{\circ} \mathrm{C}\right)$, an amorphous carbon-nitride structure is formed on the Ni-foam by the condensation of CMB complexes to melem. ${ }^{22}$ Increasing the reaction temperature to $520-550{ }^{\circ} \mathrm{C}$ results in the growth of $\beta-\mathrm{Ni}_{3} \mathrm{~N}$ with lattice parameters calculated for a hexagonal system of $a=4.581 \AA$ and $c=4.344 \AA$ (Fig. 1a and S3†). Stoichiometric deviations and carbon impurities likely lead to lattice adaptions and shifted reflections compared to other $\mathrm{Ni}_{3} \mathrm{Ns}^{23}$ Increasing the synthesis temperatures above $550{ }^{\circ} \mathrm{C}$ results in the decomposition of the metastable metal nitride through loss of the nitrogen, hence only the reflections of metallic nickel remain (Fig. S2 $\dagger$ ). It is also important to note that during the standard synthesis (at $550{ }^{\circ} \mathrm{C}$ ), the Ni-foam slightly loses its flexibility, while at higher temperatures $\left(<\sim 600{ }^{\circ} \mathrm{C}\right)$ the elasticity is completely lost making it less usable for electrochemical applications.

We found that the use of the supramolecular precursor is mandatory for the formation of $\mathrm{Ni}_{3} \mathrm{~N}$. Fig. $\mathrm{S} 4 \dagger$ compares images of Ni-foams, either modified with the CMB complex or melamine. The use of melamine results in the growth of a thick carbon-nitride layer on the surface of the Ni-foam which could not be removed with common physical methods. However, the CMB complex carbon-nitride forms a loose, removable powder while the surface of Ni-foam is modified. Strong intermolecular
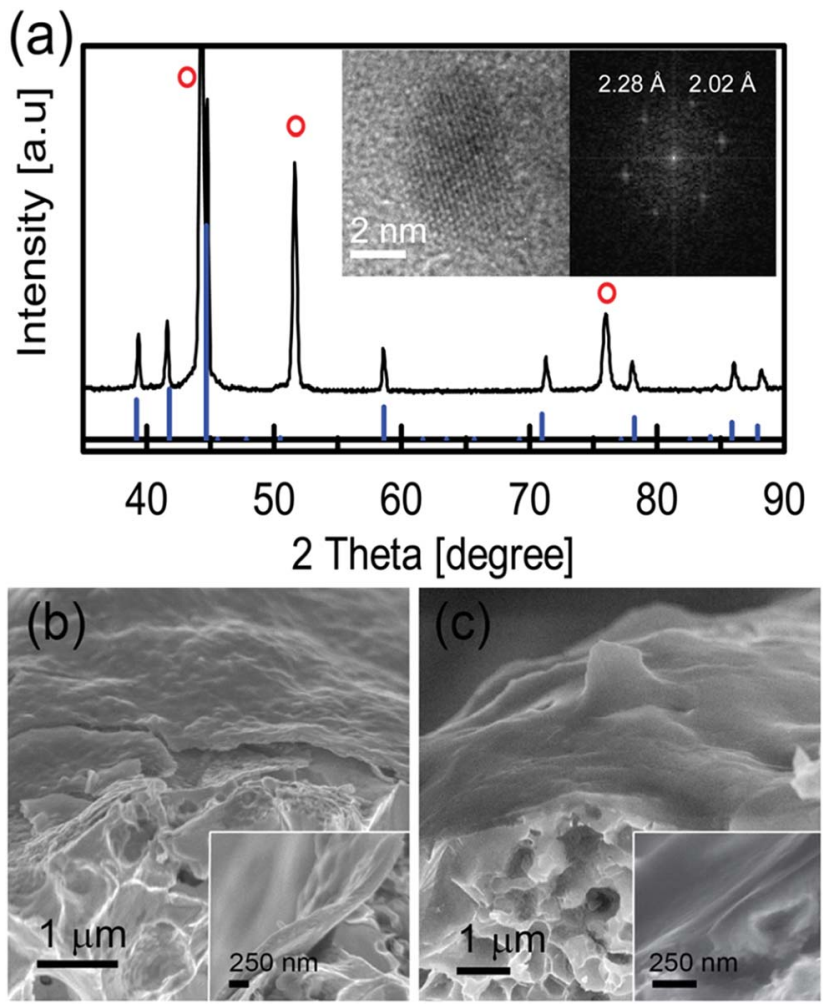

Fig. 1 (a) $\mathrm{X}$-ray diffraction pattern of a $\mathrm{Ni} / \mathrm{Ni}_{3} \mathrm{~N}$-foam with the reference pattern of $\mathrm{Ni}_{3} \mathrm{~N}$ [ICDD 04-007-3753]. The red circles indicate $\mathrm{fcc}-\mathrm{Ni}$ and assign reflections of the pristine foam. The in-set shows a representative HRTEM image and the corresponding (Fast Fourier Transforms) FFT pattern of $\mathrm{Ni}_{3} \mathrm{~N}$ particles that form on the electrode surface. The lattice fringes that match well with $d(110)$ and $d(111)$ of $\beta$ $\mathrm{Ni}_{3} \mathrm{~N}$; (b) SEM images of the modified foam before; (c) and after the removal of the carbon-nitride layer.

hydrogen bonds within CMB apparently allow smooth modification of the foam without massive intergrowth of carbonnitride by-products with the foam surface. The synthetic approach is flexible and equally allows growth of nickel sulfide by exchanging melamine with trithiocyanuric acid in the complex. The modification of the foam with this complex results in the formation of a homogenous $\mathrm{Ni} / \mathrm{Ni}_{3} \mathrm{~S}_{2}$ layer as shown in Fig. S5. $\uparrow$ The electrochemical characterization of the $\mathrm{Ni} / \mathrm{Ni}_{3} \mathrm{~S}_{2}$ is however beyond the scope of this paper.

SEM images of the modified foam in comparison to the pristine Ni-foam are shown in Fig. 1, S6 and S7. $\dagger$ While the unmodified Ni-foam surface is rather smooth the modified $\mathrm{Ni}$ is covered with a thin layer $(\sim 300 \mathrm{~nm})$ that is composed of $\mathrm{Ni}_{3} \mathrm{~N}$ and amorphous carbon-nitride according to XRD (Fig. 1a), XPS and HRTEM. More detailed, HRTEM analysis shows that the layer contains small particles $(<10 \mathrm{~nm})$ with lattice fringes corresponding to $\mathrm{Ni}_{3} \mathrm{~N}$ (Fig. 1a, inset).

XPS measurements of the foam further confirm the formation of carbon-nitride along with $\mathrm{Ni}_{3} \mathrm{~N}$ on the surface (Fig. 2). For the $\mathrm{N}$ 1s spectrum several binding energies can be distinguished. The main signal shows occurrence of $\mathrm{C}-\mathrm{N}-\mathrm{C}$ groups $(398.9 \mathrm{eV})$ and tertiary nitrogen groups $(399.6 \mathrm{eV})$, which can be attributed to carbon nitride, ${ }^{22}$ alongside the metal nitride peak 

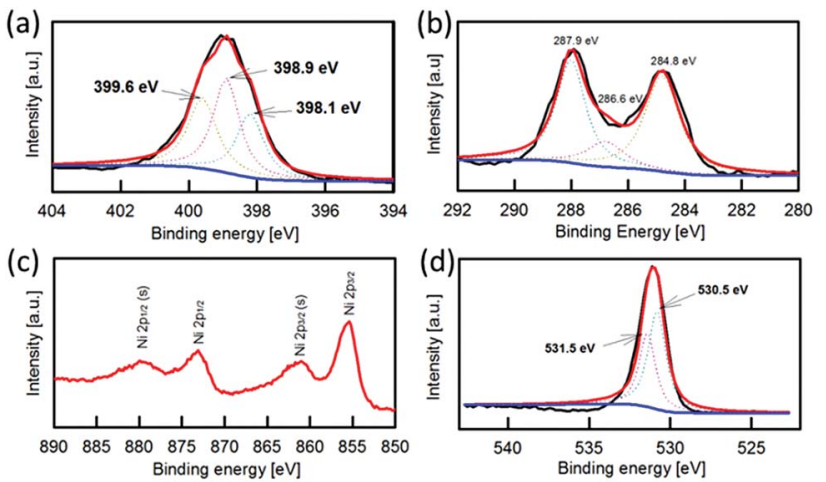

Fig. 2 (a) High-resolution XPS spectra of $N$ 1s; (b) high-resolution XPS spectra of $C 1$ s before carbon-nitride removal; (c) high-resolution XPS spectra of $\mathrm{Ni} 2 \mathrm{p}$ after the carbon-nitride removal (s stands for satellite); (d) high-resolution XPS spectra of $O 1 \mathrm{~s}$. Black corresponds to the experimental, red to the fitting curve and blue to the background.

at smaller binding energy $(398.1 \mathrm{eV}) .{ }^{24}$ In addition, the $\mathrm{C} 1 \mathrm{~s}$ spectrum shows two main peaks for aromatic $\mathrm{C}-\mathrm{C}$ and $\mathrm{C}-\mathrm{N}-\mathrm{C}$ bonds at $284.8 \mathrm{eV}$ and $287.9 \mathrm{eV}$, respectively. ${ }^{22}$ The final step in the preparation of the electrocatalyst includes the removal of the carbon nitride that covers the foam by several cyclic voltammetry scans at positive voltages. Fig. S8a $\uparrow$ shows the 10 first oxidation cycles of the modified Ni-foam in which a strong oxidation peak evolves at $\sim 1.5 \mathrm{~V} v s$. RHE.

Fig. $3 \mathrm{a}$ and $\mathrm{S} 8 \mathrm{~b} \dagger$ compare the $5^{\text {th }}$ and the $500^{\text {th }}$ first $\mathrm{CV}$ cycles of the pristine and the modified foam. Only with the later, a
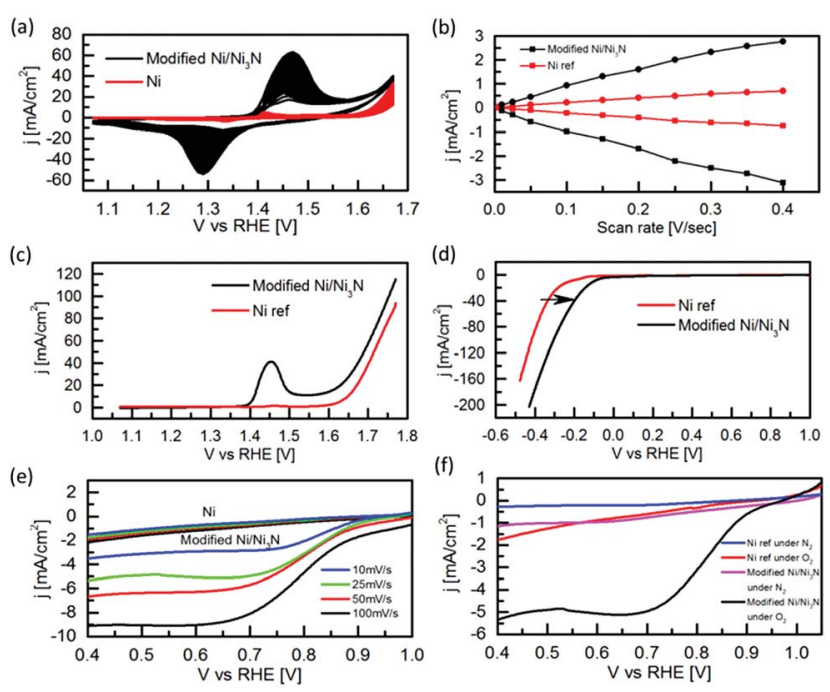

Fig. 3 (a) Cyclic voltammetry measurements ( $25 \mathrm{mV} \mathrm{s}^{-1}$ scan rate) (b) cathodic and anodic charging currents measured at $0.86 \mathrm{~V}$ vs. RHE plotted as a function of scan rate (the determined double-layer capacitance values of the system are given in Table S1 $\dagger$ ) (c) linear sweep voltammetry curves (LSV, $1 \mathrm{mV} \mathrm{s}^{-1}$ scan rate) for the oxygen evolution reaction and (d) hydrogen evolution reaction of the $\mathrm{Ni} / \mathrm{Ni}_{3} \mathrm{~N}$ foam compared to the original $\mathrm{Ni}$-foam. (e) Oxygen reduction reaction with the foams recorded at different scan rates and ( $f$ ) a performance comparison in nitrogen and oxygen saturated solution $\left(25 \mathrm{mV} \mathrm{s}^{-1}\right.$ scan rate). All the measurements were performed in $1 \mathrm{M} \mathrm{KOH}$ solution. strong oxidation (at $\sim 1.5 \mathrm{~V}$ vs. RHE) and reduction peak (at $\sim 1.35 \mathrm{~V} v s$. RHE) evolve during the cycling while the initially transparent $\mathrm{KOH}$ solution changes to yellowish, due to carbonnitride dissolution from the electrode (Fig. S9†). The oxidation of water with $\mathrm{Ni}$ in alkaline solution requires several pre-steps. The first step (0.5-1.35 V vs. RHE) is the formation of stable $\mathrm{Ni}(\mathrm{OH})_{2}$, which is an irreversible process and occurs only in the first cycles. At higher potentials $(E>1.35 \mathrm{~V})$, the $\mathrm{Ni}(\mathrm{OH})_{2}$ species is reversibly oxidized to NiOOH. ${ }^{25}$ The formation of $\mathrm{NiOOH}$ is required to catalyze the OER that sets in at higher potentials $(E>1.53 \mathrm{~V})$. In our measurements, we found that the intensity of the NiOOH oxidation peak reaches a maximum and does not change after $\sim 500 \mathrm{CV}$ cycles (Fig. S8a and $\mathrm{b}, \dagger 3 \mathrm{a}$ ). The strong intensity of the $\mathrm{NiOOH}$ formation peak indicates that the modification increases the amount of the active Ni species on the surface.

Ni-foams exhibit high ECSAs, which is one of their advantages for the utilization in electrochemical devices. The ECSA of the foams were determined by double-layer capacitance measurements (Fig. 3b and S8d). The measurements show a 5times higher ECSA for the modified foam, by assuming identical specific capacitance for both (Table S1†). This high electrochemically-active surface area (ECSA) likely results from surface restructuration processes and etching during the growth of $\mathrm{Ni}_{3} \mathrm{~N}$. Moreover, the integration of the $\mathrm{Ni}^{2+/ 3+}$ oxidation wave indicated that the amount of active $\mathrm{Ni}$ species for water oxidation was enhanced by a factor of 52 . Therefore, the number of potential catalytically active sites for water splitting is dramatically increased upon modification. It should be noted that all further measurements in this paper were conducted on the modified foam after 500 oxidation cycles.

As mentioned, the intense oxidation peak strongly suggests formation of a nickel hydroxide layer on the $\mathrm{Ni}_{3} \mathrm{~N} / \mathrm{Ni}$ surface. XPS measurement of the foam after 500 oxidation cycles clearly confirms the formation of $\mathrm{Ni}(\mathrm{OH})_{2}$ on the surface ${ }^{19,26}$ (Fig. 2c). Moreover, the N 1s signal totally disappeared (Fig. S10a $\dagger$ ) and a new hydroxide peak (530.5 eV) evolved in the $\mathrm{O} 1 \mathrm{~s}$ spectrum, ${ }^{26}$ suggesting that the $\mathrm{Ni}(\mathrm{OH})_{2}$ replaces parts of the $\mathrm{Ni}_{3} \mathrm{~N}$ layer. In addition, the removal of the carbon-nitride also becomes evident from the $\mathrm{C} 1 \mathrm{~s}$ spectrum (Fig. $\mathrm{S} 10 \mathrm{~b} \dagger$ ), in which the peak for $\mathrm{C}-\mathrm{C}$ bond dominates $(284.7 \mathrm{eV})$ along with oxidized carbon (288.6 eV).

The partial removal of the side product, the amorphous carbon-nitride layer is also evidenced by the HRSEM images of the foam after the $\mathrm{CV}$ cycles (Fig. S11 $\dagger$ ). In addition, cross section images show that the thickness of the layer decreases to $\sim 100 \mathrm{~nm}$, which is probably due to the removal of the carbon nitride layer (Fig. 1c and S7†), and EDX measurements of the modified foam (before and after 500 oxidation cycles) support the creation of a hydroxide layer by the detection of a clear oxygen signal (Fig. S12 $\dagger$ ). The surface of the activated foam is rougher and covered with small particles $(<50 \mathrm{~nm})$. In order to confirm that the nanoparticles visible in SEM (Fig. S11 $\dagger$ ) are Ni hydrate/hydroxide on the $\mathrm{Ni} / \mathrm{Ni}_{3} \mathrm{~N}$ surface we conducted EDX line scans. Fig. S11 and S13† show the SEM images and the corresponding line scans of the modified and the original $\mathrm{Ni} / \mathrm{Ni}_{3} \mathrm{~N}$ foams, respectively. This proves a rather homogeneous 
increase of surface oxide concentration along with the diameter $(\sim 50 \mathrm{~nm})$ of the patches. However, despite the conversion of the surface to $\mathrm{Ni}(\mathrm{OH})_{2}$, the XRD data after the electro-oxidation, approves the presence of the metal nitride in the bulk sample (Fig. S14b $\dagger$ ).

Linear sweep voltammetry scans (LSV) of the activated Nifoam towards positive potentials show higher current density in the formation of $\mathrm{NiOOH}$, which leads to a higher catalytic current density for the OER than the pristine foam. In addition, the overpotential for the OER is $\sim 60 \mathrm{mV}$ lower with the modified Ni-foam. However, the lower overpotential and the enhanced current density in the OER region can mainly be attributed to the extensive formation of $\mathrm{Ni}(\mathrm{OH})_{2}$ that further oxidize to active $\mathrm{NiOOH}$.

As discussed before, the oxidation of $\mathrm{Ni} / \mathrm{Ni}_{3} \mathrm{~N}$ to $\mathrm{Ni}(\mathrm{OH})_{2}$ and subsequently to NiOOH on the electrode surface is thought to be the essential pre-step to oxygen evolution. According to the above data the presence of $\mathrm{Ni}_{3} \mathrm{~N}$ seems to promote the formation of these hydroxy/oxohydroxy phases. The atomic displacement caused by incorporation of nitrogen to the nickel matrix goes in hand with structural convergence towards these hydroxide phases (fcc- $\mathrm{Ni} \rightarrow \beta-\mathrm{Ni}_{3} \mathrm{~N}$ ) and weakening of metalmetal bonds, hence likely supports subsequent oxidation during electrolysis from an energetic viewpoint (Fig. S3 and $\mathrm{S} 15 \dagger)$. Furthermore, the increase of the electrochemical activity for the OER can be also attributed to the physical roughening of the $\mathrm{Ni}$ surface and to the formation of $\mathrm{Ni}_{3} \mathrm{~N}$ nanoparticles (Fig. 1a).

Fig. 3d compares LSV curves for the HER of the modified and the pristine Ni-foam. It is important to note that without electrochemical activation that goes in hand with carbon nitride removal (Fig. S9†) the activity of the modified foam is lower (Fig. S16 $\dagger$ ) and does not change after 500 cycles toward negative potentials (from 1 to $-0.5 \mathrm{~V} v s$. RHE). For the pristine Ni-foam the current density also increases after 500 cycles (Fig. S17†), and the overpotential remains almost constant ( 150-180 mV). In contrast the modified foam exhibits a remarkably low overpotential of $\sim 50 \mathrm{mV}$ and the current density is twice as high. To the best of the authors' knowledge this overpotential is amongst the lowest for the HER with non-noble metal catalysts ${ }^{27}$ and slightly higher than that of Pt (Fig. S18†).

To confirm that $\mathrm{Ni}_{3} \mathrm{~N}$ is essential for the electrocatalytic activity in the OER and HER we modified a Ni foam with $\mathrm{Ni}(\mathrm{OH})_{2}$, as previously reported (Fig. S19†). ${ }^{19}$ In the OER, the $\mathrm{Ni}(\mathrm{OH})_{2}$ exhibited similar performance as the $\mathrm{Ni}_{3} \mathrm{~N} / \mathrm{Ni}$ electrodes (Fig. S19a†). We note the changes in the current densities can be attributed to the amount of $\mathrm{Ni}(\mathrm{OH})_{2}$ on the surface. However, the importance of the $\mathrm{Ni}_{3} \mathrm{~N}$ layer for the HER activity is clearly shown in Fig. S19b. $\dagger$ Although the $\mathrm{Ni} / \mathrm{Ni}(\mathrm{OH})_{2}$ foam showed slightly higher activity than the pristine $\mathrm{Ni}$, the $\mathrm{Ni}_{3} \mathrm{~N} / \mathrm{Ni}$ foam demonstrated significantly smaller overpotential along with higher current densities in the HER. In addition, the Tafel slope for both, $\mathrm{Ni}_{3} \mathrm{~N} / \mathrm{Ni}$ and $\mathrm{Ni} / \mathrm{Ni}(\mathrm{OH})_{2}$ exhibited classical Volmer-Heyrovsky behavior $\left(\sim 120 \mathrm{mV} \mathrm{dec}^{-1}\right)$, which is similar to most Ni-based materials in alkaline water electrolysis (Fig. S20†). The Tafel slope of the $\mathrm{Ni} / \mathrm{Ni}_{3} \mathrm{~N}$ for the OER side (Fig. S21†) showed a typical value of $\sim 60 \mathrm{mV} \mathrm{dec}{ }^{-1} .^{28}$
Furthermore, we characterized the other CMB modified foams, which were prepared at 475 and $550{ }^{\circ} \mathrm{C}$ that are not modified with $\mathrm{Ni}_{3} \mathrm{~N}$. In all cases both, the OER and HER performances (current densities and onset potentials) were lower than with the pristine Ni-foam and did not show any significant improvement with cycling (Fig. S22†). Hence, the superior performance of the modified foam in HER is likely due to the presence of the $\mathrm{Ni}_{3} \mathrm{~N} / \mathrm{Ni}(\mathrm{OH})_{2}$ junction and not because of the carbon-nitride layer.

For the alkaline HER, water dissociation and hydrogen formation rates are decisive for the productivity. $\mathrm{M} / \mathrm{M}(\mathrm{OH})_{2}$ catalysts show good productivity because water dissociation is readily achieved with the metal hydroxide, while the protons diffuse to the nearby electron-rich metal nitride surface for the reduction..$^{19}$ Recent activity evaluations of different $\mathrm{M} / \mathrm{M}(\mathrm{OH})_{2}$ couples unveiled the $\mathrm{Ni} / \mathrm{Ni}(\mathrm{OH})_{2}$ pair to be the most active for the alkaline HER. Here, we show that the activity of $\mathrm{Ni}_{3} \mathrm{~N}$ / $\mathrm{Ni}(\mathrm{OH})_{2}$ is even higher than the one of the pure nickel electrode, owing to the advantageous electronic configuration of the metal nitride for the hydrogen adsorption and liberation.

It was recently shown by Boettcher $e t a l$. that Fe impurities in the $\mathrm{KOH}$ solution can play a critical role in the activity enhancement of Ni-based electrocatalysts for OER. ${ }^{29}$ To study the influence of the Fe impurities on our catalysts we measured the HER and OER in Fe-free KOH solution that was prepared as previously described ${ }^{29}$ (Fig. S23 $\dagger$ ). For the HER, the electrocatalyst did not demonstrate any noticeable change in activity in the Fe-free $\mathrm{KOH}$ solution while the Fe impurities seem to have a small influence on the OER (by slightly quenching the oxidation of $\mathrm{Ni}^{2+}$ to $\mathrm{Ni}^{3+}$ ). The influence of the $\mathrm{Fe}$ impurities on the electrocatalytic performance of the Ni-foam seems minor in our study, because of the foams high surface area and the low Fe concentration in the $\mathrm{KOH}$ solution, which results in relatively low Fe content in the foam compared to a smooth/thin Ni layer.

The advantage of the modified Ni-foam is also demonstrated in the oxygen reduction reaction (ORR). In general, ORR measurements are carried out using a rotating disk electrode (RDE) to increase the diffusion rate of oxygen to the electrode. ${ }^{30}$ However, due to the monolithic character of the foam it was not possible to use an RDE setup. Moreover, due to strong measurement noise caused by the movement of the electrode in the oxygen stream, it was not possible to bubble oxygen during the measurement, but only before. Consequently, the presentation of ORR results solely compare the activity of the modified foam to the pristine Ni-foam, without detailed quantitative analysis. Fig. 3e shows the LSV profiles of the foams, collected at different scan rates in oxygen- or nitrogen-saturated solution. While the unmodified Ni-foam has no electrocatalytic activity in the ORR, the LSVs of the modified foam clearly shows favorable electrocatalytic behavior. At this stage, it cannot be excluded that remaining carbon impurities (which is a well-known electrocatalyst for ORR) contribute to the electrocatalytic activity. ${ }^{30}$ The ORR activity is also demonstrated in Fig. 3f, in which both LSV curves $\left(25 \mathrm{mV} \mathrm{s}^{-1}\right)$ in either nitrogen or oxygen saturated solution are shown. The modified $\mathrm{Ni} / \mathrm{Ni}_{3} \mathrm{~N}$ foam exhibits low overpotential for the ORR together with high current densities. However, we note again that due to the monolithic nature of the 
foam it is not possible to further analyze the mechanism of this reaction in the current work.

In order to test the stability of the modified $\mathrm{Ni}$-foam as both HER and OER catalyst, we recorded 500 cyclic voltammetry scans, plus for the HER the changes of the overpotential at 10 and $100 \mathrm{~mA} \mathrm{~cm}{ }^{-2}$ for two hours. For the OER, only the most critical measurements at $100 \mathrm{~mA} \mathrm{~cm}{ }^{-2}$ were performed. Fig. $4 \mathrm{a}$ shows HER chronoamperometry measurements at 10 and 100 $\mathrm{mA} \mathrm{cm}{ }^{-2}$ and compares the initial and final overpotentials of the two foams. At a current density of $10 \mathrm{~mA} \mathrm{~cm}{ }^{-2}$ the overpotentials remain almost constant for both foams. The overpotential needed to achieve this current density is remarkably lower for the modified foam $(\sim 100 \mathrm{mV})$ than for the pristine foam $(\sim 200 \mathrm{mV})$. The superior performance of the modified foam becomes even more evident at higher current density (100 $\mathrm{mA} \mathrm{cm}{ }^{-2}$ ) where the overpotential is only $260 \mathrm{mV}$ compared to $400 \mathrm{mV}$. Moreover, the overpotential remains almost constant, with a drop of only $13 \mathrm{mV}$ after two hours while the overpotential for the original foam increases by $\sim 60 \mathrm{mV}$ in $2 \mathrm{~h}$. Given these values, the performance of the modified foam is at the forefront of non-noble metal based HER electrocatalysts. Additional information on the stability of the modified foam is given by the measurement of the current voltage properties for 500 cycles at a scan rate of $25 \mathrm{mV} \mathrm{s}^{-1}$. Fig. $4 \mathrm{~b}$ shows the first and the five-hundredth scan of the modified foam. The electrode demonstrates high stability, with negligible change in the onset potential along with just $\sim 15 \%$ current loss. However, these current density losses can be mainly attributed to the formation of gas bubbles, which accumulated during the scanning.

Fig. 4c compares OER chronoamperometry measurements of the modified and the pristine foam at $100 \mathrm{~mA} \mathrm{~cm}^{-2}$ for $1 \mathrm{~h}$. The advantage of the modified foam is demonstrated with the lower overpotential which is required to support this high current $(\sim 0.48 \mathrm{~V} v s .0 .52 \mathrm{~V})$ and even more by its high stability and the low overpotential changes during the measurement. While the overpotential of the original foam increases by $\sim 90 \mathrm{mV}$ after one hour, the overpotential of the modified foam increases by
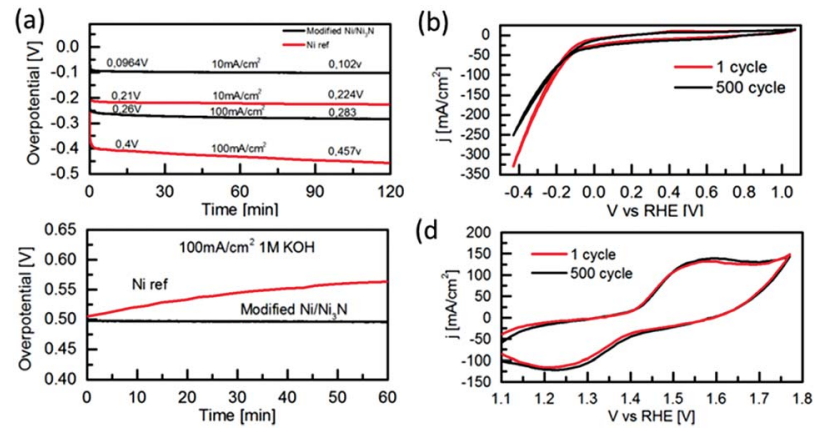

Fig. 4 (a) Electrolysis (HER) at 10 and $100 \mathrm{~mA} \mathrm{~cm}^{-2}$ per geometric area. (b) Cyclic voltammetry measurements. The red and the black curves stand for the first and the five hundredth scan respectively. Electrolysis (OER) at $100 \mathrm{~mA} \mathrm{~cm}{ }^{-2}$ per geometric area (c) and cyclic voltammetry measurements (d). The red and the black curves stand for the first and the five hundredth scans, respectively. For all the measurements $1 \mathrm{M} \mathrm{KOH}$ in water was used as electrolyte. Cyclic voltammetry curves were recorded at a scan rate of $25 \mathrm{mV} \mathrm{s}^{-1}$. only $\sim 15 \mathrm{mV}$ with more than $90 \%$ Faradaic efficiency. The stability of the modified Ni-foam was also tested by measuring the current voltage properties for 500 cycles at a scan rate of $25 \mathrm{mV} \mathrm{s}^{-1}$ (Fig. 4d). The current density and the overpotential of the modified foam did not change after $500 \mathrm{CV}$ scans, demonstrating the high stability of the modified foam. In addition, longer stability measurements for HER and OER $\left(100 \mathrm{~mA} \mathrm{~cm}^{-2}\right.$ at $25^{\circ} \mathrm{C}$ for $12 \mathrm{~h}$ and $250 \mathrm{~mA} \mathrm{~cm}^{-2}$ at $61{ }^{\circ} \mathrm{C}$ for $2 \mathrm{~h}$ ) which further confirmed the high stability of the modified foam are shown in Fig. S24 and S25. $\dagger$ Recent work by Chorkendorff et al. showed that the electrochemical stability is not enough to judge the total stability of the material due to partially dissolution of the electrocatalyst. ${ }^{31}$ In order to confirm the stability of the modified foam we tracked the Ni content with ICP-OES (inductively coupled plasma optical emission spectrometry) of the $\mathrm{KOH}$ solution before and after 500 oxidation scans. The Ni content was in both cases below $1 \mathrm{ppm}$ and with no noteworthy differences of the signals, indicating insignificant material losses through dissolution processes.

The stability of the $\mathrm{Ni} / \mathrm{Ni}_{3} \mathrm{~N}$ foam was also confirmed by the XRD measurements and the SEM images of the modified foam after all electrochemical measurements (Fig. S13†). The XRD pattern of the nickel nitride remained unchanged, suggesting that the core material is still composed of nickel nitride on Ni.

The properties of the modified foam were also measured in extreme alkaline environment (6 M KOH). Fig. S26a† compares the LSV curves of the hydrogen evolution reaction of the modified foam and the original foam. The overpotential of the modified foam remains low $(\sim 85 \mathrm{mV})$ and the current densities very high. In contrast, the original foam exhibits an overpotential of around $200 \mathrm{mV}$ and 2 times lower current densities. Most importantly, the modified foam exhibits high stability in the chronoamperometry study also under these "accelerated ageing" conditions (Fig. S26b $†$ ). The overpotential of the modified foam remained almost constant for $1 \mathrm{~h}$ at $100 \mathrm{~mA} \mathrm{~cm}^{-2}$. In addition, the overpotential for the OER is reduced down to $280 \mathrm{mV}$, and high current densities can be obtained (Fig. S26c †े). It is important to note that in this strong alkaline solution the original foam also exhibits low overpotential for the OER.

\section{Conclusions}

In conclusion, we demonstrated an efficient and generic method to modify the surface of Ni-foams with a $\mathrm{Ni}_{3} \mathrm{~N}$ layer for electrocatalytic applications. The modification of the foam also results in a five-fold increase of the electrochemically active surface area and in increase of active $\mathrm{Ni}^{2+}$ species by more than 50 times. The modified foam exhibits low overpotentials, high current densities and good stability for the hydrogen evolution reaction in alkaline solutions. The high performances in HER are explained by in situ formation of $\mathrm{Ni}$ hydroxide on the $\mathrm{Ni}$ nitride layer, potentially promoted by the structural similarities of both materials. The modified foam also exhibits enhanced activity in the oxygen evolution and reduction reaction compared to original Ni-foam. We believe that the simple modification along with the electrocatalytic properties of the 
$\mathrm{Ni} / \mathrm{Ni}_{3} \mathrm{~N}$ foam open opportunities for energy-related devices such as water electrolyzers, batteries and fuel cells.

\section{Experimental section}

\section{Synthesis of modified Ni-foam}

The CMB complexes were prepared by dissolving a $1: 1: 0.1$ mass ratio of cyanuric acid, melamine and barbituric acid $(2.1 \mathrm{~g}$ total weight) in $40 \mathrm{ml}$ of water. The dispersion was then mixed for 4 hours with an automatic shaker, inducing precipitation of the CMB complex, which was separated from solution by filtration using a Buchner funnel. The white powder was washed several times with water and dried at $60{ }^{\circ} \mathrm{C}$ in a vacuum oven. For the films preparation, a CMB powder (thin layer) was placed below and above a piece of commercial Ni foam (MTI Corporation, item number: EQ-bcnf-16 $\mathrm{m}$ ) in a ceramic crucible (topped with a ceramic cap) and calcined at different temperatures under a nitrogen flow with a heating rate of $2.3{ }^{\circ} \mathrm{C} \mathrm{min}^{-1}$ (Fig. S2a $\dagger$ ). After the cooling down, the electrodes were cleaned by a strong air stream. For further removal of powder impurities the modified foam was cycled 500 times, between 1.05 and 1.65 $\mathrm{V}(v s$. RHE) in an alkaline solution as discuss in the manuscript.

$\mathrm{Ni}(\mathrm{OH})_{2}$-modified electrodes were prepared by chemical deposition as described elsewhere. ${ }^{32}$ The pristine foam was immersed to an aqueous $\mathrm{NiCl}_{2}$ solution $(0.1 \mathrm{M})$ for $12 \mathrm{~h}$, and washed thoroughly with water before being introduced into the electrolyte. For the final oxide coverage the foam was cycled from 1 to $-0.5 \mathrm{~V} v s$. RHE until no change in the activity was observed. Purification of the $\mathrm{KOH}$ buffer was achieved according to the procedure that was described by Boettcher et al. ${ }^{29}$

\section{Characterization}

X-ray diffraction-patterns were measured on a Bruker D8 Advance instrument using $\mathrm{Cu}-\mathrm{K} \alpha$ radiation. The reference $\mathrm{Ni}_{3} \mathrm{~N}$ and $\mathrm{Ni}_{3} \mathrm{~S}_{2}$ patterns were taken from the NIST database (entry number 04-011-7280 and 04-008-8458, respectively). The surface electronic states were analyzed using X-ray photoelectron spectroscopy (XPS, Perkin-Elmer PHI 5000C). Elemental analysis was accomplished as combustion analysis using a Vario Micro device. Scanning electron microscopy (SEM) images were obtained on a LEO 1550-Gemini. Energy dispersive X-ray (EDX) analyses and investigations of the morphology by SEM were performed on a JEOL (JSM - $7500 \mathrm{~F}$ ) device equipped with an Oxford Instruments X-MAX $80 \mathrm{~mm}^{2}$ detector. A cross section of the electrodes was performed using a Helios 600, dual beam SEM, and focus ion beam (FIB) instrument. FT-IR spectra for the characterization of the compounds were recorded on a Varian1000 FT-IR spectrometer. Transmission electron microscopy (TEM) measurements were performed on a FEI TITAN microscope operated at an acceleration voltage of $300 \mathrm{kV}$. The foams were crushed in a mortar and the obtained powders were dispersed in chloroform and deposited onto copper TEM grids coated with holey carbon. ICP-OES was measured on a Varian Vista - MPX instrument equipped with a CCD detector. Aqueous calibration solutions of 2, 10 and 20 ppm were freshly prepared from Merck millipore standard solutions (1000 ppm).

\section{Electrochemical characterization}

Electrochemical tests were performed in $0.1 \mathrm{M}, 1 \mathrm{M}$ and $6 \mathrm{M}$ $\mathrm{KOH}$ in a three-electrodes cell setup with a saturated calomel electrode (SCE) as reference electrode and a platinum wire as counter electrode using a Gamry Reference 600 potentiostat (Gamry Instruments). Cyclic voltammetry was carried out at a scan rate of $25 \mathrm{mV} \mathrm{s}^{-1}$. Linear sweep voltammetry (LSV) was carried out at a scan rate of $1 \mathrm{mV} \mathrm{s}^{-1}$. All the data was not $i R$ corrected due to the high current densities values. Chronoamperometry measurements were conducted by monitoring the voltage at constant currents. The double layer capacitances were determined by $\mathrm{CV}$ in a potential window of $0.1 \mathrm{~V}$ (from $0.81 \mathrm{~V}$ to $0.91 \mathrm{~V} v s$. RHE) in the non-Faradaic region. For these measurements we used different scan rates from 50 to $400 \mathrm{mV} \mathrm{s}^{-1}$. The working electrode was held at each potential for $10 \mathrm{~s}$ before the measurement. The double-layer charging current $\left(i_{\mathrm{c}}\right)$ is equal to:

$$
i_{\mathrm{c}}=\nu C_{\mathrm{DL}}
$$

where $\nu$ is the scan rate and $C_{\mathrm{DL}}$ is the electrochemical doublelayer capacitance. Therefore, electrochemical double-layer capacitance can be extracted by plotting the double-layer charging current $\left(i_{\mathrm{c}}\right)$ as a function of the scan rate $\nu$.

For the oxygen reduction reaction (ORR), the solution was purged with $\mathrm{N}_{2}$ for 20 min before each control measurements. Afterward, the solution was purged with $\mathrm{O}_{2}$ for $20 \mathrm{~min}$ before each measurement. However, due to strong noise, during the measurement the gas flow was turned off. All measurements were referred to the reversible hydrogen electrode (RHE) by using the relationship: $\mathrm{V}_{\mathrm{RHE}}=\mathrm{V}_{\mathrm{SCE}}+0.244 \mathrm{~V}+\mathrm{pH}(0.059 \mathrm{~V}) .^{33}$ Tafel slopes were obtained by recording the current in different voltages after 10 min chronoamperometry at each voltage. The $\mathrm{O}_{2}$ evolution (only in the solution) was monitored by an oxygen probe (PreSens Precision Sensing GmbH, Fibox 3 fiber optic oxygen transmitter) in a three neck flask (not sealed). The Faradaic efficiency was calculated by

$$
\%=\frac{\text { Oxygen molecules }(\mathrm{mol})}{\text { Mol of electrons } / 4} .
$$

\section{Acknowledgements}

M.S. would like to thank "Minerva fellowship" for financial support.

\section{Notes and references}

1 L. Schlapbach and A. Zuttel, Nature, 2001, 414, 353.

2 W. F. Chen, K. Sasaki, C. Ma, A. I. Frenkel, N. Marinkovic, J. T. Muckerman, Y. M. Zhu and R. R. Adzic, Angew. Chem., Int. Ed., 2012, 51, 6131.

3 (a) N. M. Markovic, Nat. Mater., 2013, 12, 101; (b) A. Kudo and Y. Miseki, Chem. Soc. Rev., 2009, 38, 253; (c) J. R. McKone, S. C. Marinescu, B. S. Brunschwig, J. R. Winkler and H. B. Gray, Chem. Sci., 2014, 5, 865. 
4 M. S. Dresselhaus and I. L. Thomas, Nature, 2001, 414, 332. 5 (a) A. Grimaud, K. J. May, C. E. Carlton, Y.-L. Lee, M. Risch, W. T. Hong, J. Zhou and Y. Shao-Horn, Nat. Commun., 2013, 4, 2439; (b) Z. P. Shao and S. M. Haile, Nature, 2004, 431, 170. 6 J. Cai, L. Xu, J. M. Wang, L. Y. Zhang, H. Zhou, Y. Zhong, D. Chen, H. Q. Fan, H. B. Shao, J. Q. Zhang and C. N. Cao, Int. J. Hydrogen Energy, 2013, 38, 934.

7 S. Chen, J. J. Duan, M. Jaroniec and S. Z. Qiao, Angew. Chem., Int. Ed., 2013, 52, 13567.

8 (a) W. F. Chen, J. T. Muckerman and E. Fujita, Chem. Commun., 2013, 49, 8896; (b) W.-F. Chen, K. Sasaki, C. Ma, A. I. Frenkel, N. Marinkovic, J. T. Muckerman, Y. Zhu and R. R. Adzic, Angew. Chem., Int. Ed., 2012, 51, 6131.

9 A. Le Goff, V. Artero, B. Jousselme, P. D. Tran, N. Guillet, R. Metaye, A. Fihri, S. Palacin and M. Fontecave, Science, 2009, 326, 1384.

10 (a) K. A. Kuttiyiel, K. Sasaki, W. F. Chen, D. Su and R. R. Adzic, J. Mater. Chem. A, 2014, 2, 591; (b) C. C. L. McCrory, S. H. Jung, J. C. Peters and T. F. Jaramillo, J. Am. Chem. Soc., 2013, 135, 16977.

11 M. M. Jaksic, Int. J. Hydrogen Energy, 2001, 26, 559.

12 M. Gong, Y. G. Li, H. L. Wang, Y. Y. Liang, J. Z. Wu, J. G. Zhou, J. Wang, T. Regier, F. Wei and H. J. Dai, J. Am. Chem. Soc., 2013, 135, 8452.

13 I. M. Sadiek, A. M. Mohammad, M. E. El-Shakre and M. S. ElDeab, Int. J. Hydrogen Energy, 2012, 37, 68.

14 (a) W. J. Zhou, X. J. Wu, X. H. Cao, X. Huang, C. L. Tan, J. Tian, H. Liu, J. Y. Wang and H. Zhang, Energy Environ. Sci., 2013, 6, 2921; (b) N. H. Chou, P. N. Ross, A. T. Bell and T. D. Tilley, ChemSusChem, 2011, 4, 1566; (c) A. J. Esswein, Y. Surendranath, S. Y. Reece and D. G. Nocera, Energy Environ. Sci., 2011, 4, 499.

15 J. G. G. Chen, Chem. Rev., 1996, 96, 1477.

16 M. Shalom, V. Molinari, D. Esposito, G. Clavel, D. Ressnig, C. Giordano and M. Antonietti, Adv. Mater., 2014, 26, 1272.

17 B. F. Cao, G. M. Veith, J. C. Neuefeind, R. R. Adzic and P. G. Khalifah, J. Am. Chem. Soc., 2013, 135, 19186.
18 G. Clavel, V. Molinari, A. Kraupner and C. Giordano, Chem.Eur. J., 2014, 20, 9018.

19 N. Danilovic, R. Subbaraman, D. Strmcnik, K. C. Chang, A. P. Paulikas, V. R. Stamenkovic and N. M. Markovic, Angew. Chem., Int. Ed., 2012, 51, 12495.

20 R. Subbaraman, D. Tripkovic, D. Strmenik, K. C. Chang, M. Uchimura, A. P. Paulikas, V. Stamenkovic and N. M. Markovic, Science, 2011, 334, 1256.

21 M. Shalom, M. Guttentag, C. Fettkenhauer, S. Inal, D. Neher, A. Llobet and M. Antonietti, Chem. Mater., 2014, 26, 5812.

22 A. Thomas, A. Fischer, F. Goettmann, M. Antonietti, J. O. Muller, R. Schlogl and J. M. Carlsson, J. Mater. Chem., 2008, 18, 4893.

23 Z. L. Schaefer, K. M. Weeber, R. Misra, P. Schiffer and R. E. Schaak, Chem. Mater., 2011, 23, 2475.

24 A. N. Cloud, L. M. Davis, G. S. Girolami and J. R. Abelson, J. Vac. Sci. Technol., A, 2014, 32, 2.

25 R. L. Doyle, I. J. Godwin, M. P. Brandon and M. E. G. Lyons, Phys. Chem. Chem. Phys., 2013, 15, 13737.

26 M. C. Biesinger, B. P. Payne, L. W. M. Lau, A. Gerson and R. S. C. Smart, Surf. Interface Anal., 2009, 41, 324.

27 J. R. McKone, B. F. Sadtler, C. A. Werlang, N. S. Lewis and H. Gray, ACS Catal., 2013, 3, 169.

28 M. E. G. Lyons and M. P. Brandon, Int. J. Electrochem. Sci., 2008, 3, 1386.

29 L. Trotochaud, S. L. Young, J. K. Ranney and S. W. Boettcher, J. Am. Chem. Soc., 2014, 136, 6744.

30 Y. Zheng, Y. Jiao, M. Jaroniec, Y. G. Jin and S. Z. Qiao, Small, 2012, 8, 3550.

31 R. Frydendal, A. E. Paoli, P. B. Knudsen, B. Wickman, P. Malacrida, E. L. I. Stephens and I. Chorkendorff, ChemElectroChem, 2014, 12, 2075.

32 N. Danilovic, R. Subbaraman, D. Strmcnik, K.-C. Chang, A. P. Paulikas, V. R. Stamenkovic and N. M. Markovic, Angew. Chem., Int. Ed., 2012, 51, 12495.

33 D. J. G. Ives and G. J. Janz, Reference electrodes, theory and practice, Academic Press, 1961. 